\title{
Converses amb Antoni Ballester
}

\author{
Entrevistat per Antoni Gavaldà i Josep Maria Pons
}

Antoni Ballester Vallori és mestre, llicenciat i doctor en Geografia per la Universitat de les Illes Balears (1980 i 1992), mestre de primària, professor d'institut i professor associat del Departament de Ciències de la Terra de la Universitat de les Illes Balears. El 1998 es doctora en Geografia amb la tesi "La didàctica de la geografia de les Illes Balears: aprenentatge significatiu i recursos didàctics". La seva tasca en el camp de la recerca s'ha centrat en la pràctica docent. El seu projecte sobre l'aprenentatge s'ha presentat a Finlàndia, Estònia, Mèxic, Madrid, Barcelona, València... Les seves contribucions han potenciat el marc teòric de Novak, el més influent en l'educació actual. Forma part dels professors que ostenten el lideratge de rellevància mundial en l'àmbit de l'aprenentatge significatiu i els mapes conceptuals, juntament amb Cañas (Estats Units), Moreira (Brasil), Valadares (Portugal) i Fermín González (Espanya). Ha estat professor durant trenta anys i ha participat i col-laborat durant més de deu anys amb les associacions de pares i mares. És professor i coordinador de cursos i seminaris per a professors i conferències per a pares i professors. El seu llibre digital gratuït Laprenentatge significatiu a la pràctica ha rebut més de 2 milions de visites.

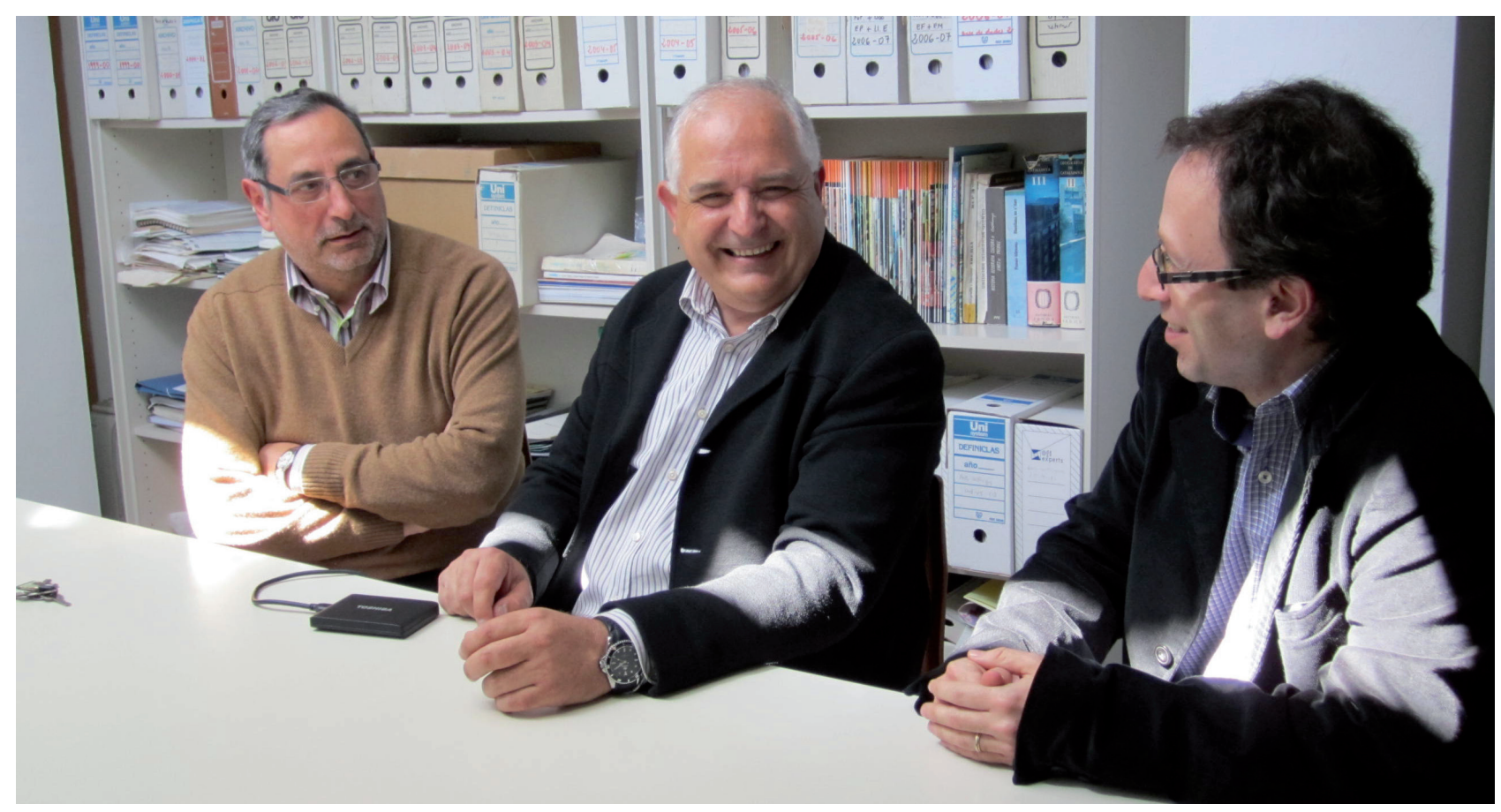


Què entenem per aprenentatge significatiu, doctor Ballester?

Bé, l'aprenentatge significatiu és una teoria d'Ausubel descrita per Novak que diu que per aprendre és molt important relacionar els conceptes, des dels més generals fins als més particulars, que és la base del llenguatge.

Es tracta d'un mètode que fins i tot utilitza la NASA, l'exèrcit americà i altres institucions. Per què?

Bé, un dels factors o de les variables clau per fer que l'aprenentatge sigui a llarg termini, és a dir, no soblidi després de l'examen, és el mapa conceptual de Novak, que és una eina similar a un esquema que el que fa és relacionar els conceptes. La NASA i l'exèrcit americà ho han utilitzat; per exemple, la NASA, per representar el coneixement cada vegada més elevat que tenen els astronautes i així poder tenir aquest coneixement estructurat, relacionat, jerarquitzat i que sigui més fàcil d’entendre per a les altres persones.

Segons aquest mètode d'aprenentatge, l'alumne podríem dir que deixa de ser un subjecte passiu a l'aula que només rep aquestes explicacions i passa a ser un subjecte actiu; per tant, això també ajuda a motivar-lo?

Bé, el que passa ara a les aules majoritàriament, no sempre perquè hi ha aules que funcionen $\mathrm{amb}$ sistemes actius, és que tenim a tot l'Estat espanyol, encara que sigui la zona de la Mediterrània, que diuen que és la que està més malament en el tema educatiu, mestres excel.lents, tenim mestres que tenen una formació excel.lent i ja els agradaria a Finlàndia, que sempre es posa com a paradigma de l'educació, tenir alguns mestres dels que tenim nosaltres a Catalunya o a les Illes, o pertot arreu. El que passa és que podem dir que aquells mestres que estan utilitzant metodologies cada vegada més innovadores funcionen millor amb els nens. A l'escola activa, si se sistematitza la feina, el mestre treballa menys d'una altra manera, de manera intel-ligent. A l'escola tradicional, l'alumne està passiu i el mestre fa una feinada. Els mestres treballen molt, encara que de vegades sembli que no, que tenen moltes vacances i totes aquestes coses que es diuen.
La diversitat dins les aules sovint és un problema difícil de gestionar. A partir de la recerca que ha realitzat, com s'hi pot fer front per treure'n profit l'alumne?

Bé, el que passa a les escoles és que hi ha molta diversitat, els alumnes són molt heterogenis, no solament pel que fa a característiques de facilitat per aprendre, sinó també d'idioma o de cultura, hi pot haver moltes diferències. Hi ha uns alumnes sempre, a qualsevol aula, molt avançats, alumnes que estan a la meitat de la classe i alumnes més endarrerits. Quina és la tendència dels mestres? A fer la proposta del que han de fer cap a la meitat. Si fem la proposta que hem de fer cap a la meitat, els més avançats s'avorreixen perquè ja ho saben i els més endarrerits no hi arriben. Si la proposta és massa baixa o massa fàcil, els de la meitat i avançats s'avorreixen, i per als més avançats també passa el mateix, si ho fem massa amb la proposta massa alta. Aleshores, la millor manera és fer el treball obert, que és dir el tema que han de fer i el material, però la manera de fer-ho depèn de cada alumne. Això està explicat al llibre digital que hem publicat.

Precisament, aquest llibre digital es pot consultar a un lloc web: <www.aprenentatgesignificatiu.com $>$, que està en diversos idiomes. I aquí es pot consultar tot allò relacionat amb aquest mètode d'aprenentatge.

Sí, al web <www.aprenentatgesignificatiu.com> veuran a baix que té com una bandereta i la poden consultar també en castellà i en anglès. No són unes pàgines que estiguin traduïdes, amb la mateixa informació, sinó que cada pàgina té informació diferent, però sempre molt relacionada amb l'aprenentatge significatiu, hi trobaran vídeos i experiències, pràctiques d'aplicació que s'han fet a les Canàries sobre aquesta metodologia, etc.

Això li volia preguntar: quines $i$ quantes escoles apliquen avui en dia aquest mètode $i$ quin interès hi ha per part dels docents?

Aquest llibre es va publicar a Internet fa uns quants anys. El Govern de Canàries, sense conèixer-nos a nosaltres $i$ sense haver parlat $\mathrm{amb}$ nosaltres, va agafar el llibre, el va posar en mans de coordinadors i coordinadores de cada un dels 


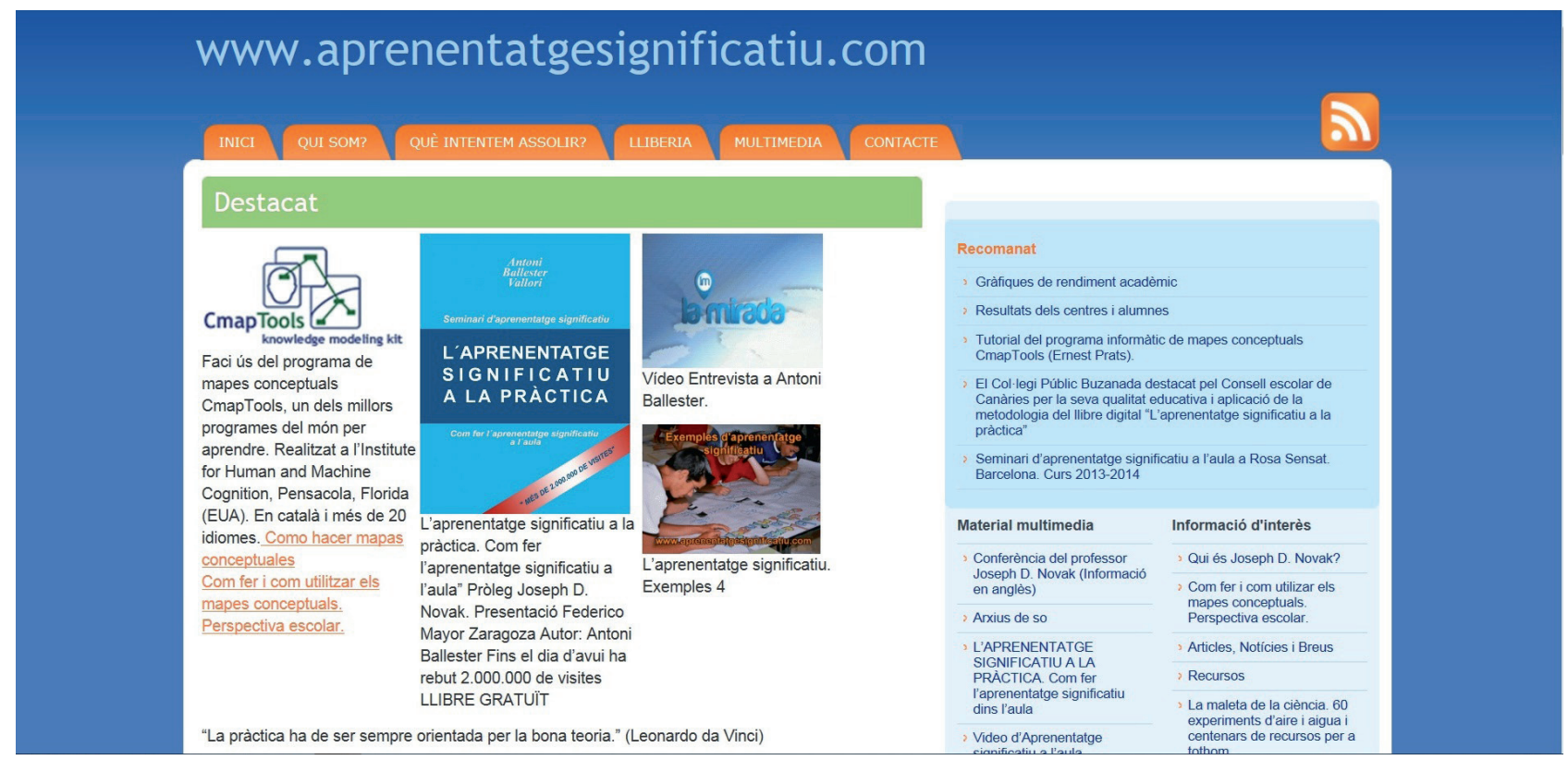

centres que tenien a Tenerife a un programa d'atenció preferent i van aplicar aquest llibre a les seves escoles. Una vegada va funcionar a Tenerife, ho van dur cap a les altres illes amb molt bon resultat, i molt bona satisfacció també dels pares, dels alumnes, i també del professorat i dels centres. També s'ha aplicat a Mèxic, s'ha aplicat a Colòmbia, a Bolívia, bé, a diferents llocs del món.

\section{I aquí a Catalunya?}

Bé, aquí a Catalunya ara hem fet aquestes xerrades a la Universitat Rovira i Virgili a Tarragona, està previst fer el curs "Aplicació pràctica de l'aprenentatge significatiu" de manera presencial de setembre a maig el curs que ve a Rosa Sensat, a l'Associació de Mestres Rosa Sensat, com una reunió cada mes un dissabte al matí, tres hores de reunió per aplicar cada un dels mòduls del llibre, i la idea és que tant de Girona com de Tarragona i Barcelona puguin venir persones que tinguin el perfil de formadors per poder coordinar als seus centres aquesta metodologia.

L'ensenyament de les CCSS a educació primària presenta un alt grau de complexitat, atès que són unes disciplines que impliquen una abstracció per a una comprensió efectiva. Què n’opineu d'aquesta màxima?
Bé, el que passa és que sovint el coneixement del medi i de manera majoritària es fa per memorització lineal de la informació, és a dir, aprendre repetint, $i$ avui sabem que no facilita la comprensió efectiva, sinó l'oblit al cap de poc temps; segons Novak, l'aprenentatge per repetició al cap de sis mesos ja esta oblidat totalment.

\section{Com s'ha de treballar amb els alumnes per acon- seguir aquest aprenentatge significatiu?}

A fi que l'aprenentatge sigui significatiu i formi bones estructures de coneixement a la ment de l'alumne, cal, a més, que l'aprenentatge sigui relacionant els conceptes amb les coses que l'alumne sap de la vida quotidiana, de la vida real de l'alumne fora de l'aula, és a dir, amb el medi. Com podem fer que l'alumne aprengui coneixement del medi si no ho relacionam també amb el medi de l'alumne? També la motivació és fonamental: crear interès per l'activitat educativa. Motivar i motivar, així no s'interromp el ritme de la classe. El professorat aconsegueix motivar de tres formes: proposa una activitat atractiva; lloa els seus avenços: el reforç positiu els anima a superar-se, i usa reforços externs com ara la nota o recompenses externes. 
D’altra banda, quines estratègies didàctiques hauria de seguir un mestre per portar realment l'aprenentatge significatiu a les aules de primària?

El professorat hauria d'aplicar les variables clau de l'aprenentatge significatiu a la pràctica:

El treball obert: per poder treballar amb alumnes diferents. La motivació: per millorar el clima de l'aula i tenir l'alumnat interessat en el treball. El medi: per relacionar amb l'entorn. La creativitat: per potenciar la imaginació i la intelligència. El mapa conceptual: per relacionar i connectar els conceptes. Ladaptació curricular: per a l'alumnat de necessitats especials prepararà el clima de l'aula per tenir èxit amb el mapa conceptual de Novak, així farà que els alumnes aprenguin de manera atractiva. Els mestres tenen molts recursos didàctics i estratègies seves i dels altres mestres de les mateixes escoles amb moltes idees i materials diversificats per poder fer amb el nord d'aquestes variables que predeterminen l'aprenentatge de l'alumne. Al nostre llibre digital s'han desenvolupat les estratègies didàctiques i els exemples per poder dur a terme la metodologia.

Els continguts són una peça essencial del sistema. Com s'haurien de triar els continguts que cal treballar per cicles?

Bé, els continguts són una peça clau del sistema, jo he treballat la metodologia i no sóc un especialista en el tema dels continguts, però, per exemple, en el tema de l'escala, sembla clar fins ara que no podem tenir un visió reduccionista local ni sols una visió global i mundial, sinó que hem d'anar treballant en diferents escales. Avui dia els alumnes, a través de la televisió i Internet, tenen informació de qualsevol punt del món igual que de l'àmbit local; per tant, hem d'emprar diferents escales. No pot ser que la paraula París com a capital de França a l'escola la trobin a sisè de primària quan estudien Europa, és clar que la poden trobar des d'educació infantil si tenim en compte aquest joc d'escales. El que també me sembla clar és que cal globalitzar, globalitzar i relacionar. Una estratègia bona és, dels 14 o 15 temes que es treballaran en cada curs escolar, ajuntar-ne que siguin semblants, com ara la casa i la família o clima i paisatge. D'aquesta manera, podem passar de 15 temes a 8 temes, un cada mes, i així tenir temps per aprendre bé, consolidar l'aprenentatge i fer, per exemple, el Dia del Llibre, el Dia de la Pau o una excursió, sense presses gaudint de les activitats de manera relaxada.

En agradaria poder divulgar la metodologia didàctica que cal seguir per aconseguir els continguts. Pot oferir-nos una visió sintètica, però real? Sí, les variables que he comentat, però la millor manera és que vagin al web $<w w w$.aprenentatgesignificatiu.com>, on trobaran, a més del llibre digital, recursos, vídeos i tot el material que cal per portar la metodologia endavant; allà el material és segur. No es pot resumir en unes frases o comentar en el temps d'un cafè, la metodologia, per fer-la bé, cal aprendre-la bé, sense presses i amb material segur.

Les seves propostes teòriques s'han concretat en l'àmbit específic, però especialment en la didàctica de la geografia. Un dels eixos de treball és el treball amb el mapa conceptual. Podria explicar detalladament com s'ha de gestionar un mapa conceptual per les CCSS, amb alumnes dels tres cicles de primària, ben diferenciats?

El mapa conceptual a educació infantil es pot fer amb dibuixos o fotografies i després ja amb paraules il.lustrades, a l'inici amb ajuda, és clar. Es pot treballar des dels tres anys. A cicle mitjà els alumnes poden construir els seus mapes conceptuals, però primer hem d'aprendre a fer-los nosaltres (posant sempre les paraules d'enllaç i un concepte a cada el-lipse, ja que els mapes conceptuals són mapes de conceptes, no de frases); els podrem utilitzar com a avaluació inicial, per guiar l'aprenentatge o com a síntesi d'un tema. Quan tenen més eficàcia és a l'hora de guiar l'aprenentatge, és a dir, mentre es va fent el tema. A cicle superior de primària els podem utilitzar com a tercer cicle augmentant el nombre de conceptes, cercant informació, per exemple, a llibres, a revistes o a Internet.

La pedagogia diu com s'ha de realitzar l'aprenentatge, i molts professionals només escolten la teoria sense resoldre la pràctica. Tenint com tenim 
un model pràctic en vostè, ens agradaria que ens detallés una unitat de CCSS del començament al final. Segur que els nostres alumnes i els mateixos mestres en traurien molt de rendiment.

D’acord, però és molt difícil per a mi detallar una unitat didàctica de ciències socials en el temps i l'espai que tenim en aquesta entrevista. Bé, en lloc d'unitat didàctica, jo parlaria d'experiència d'aprenentatge, que és un concepte tal vegada més global i més adient en la metodologia de l'aprenentatge significatiu. Per veure com és una experiència d'aprenentatge molt completa poden anar a Internet i cercar "Mururoa a l'aula" (<http://www. aprendizajesignificativo.es/antoniballester/cat/ innovacion.htm $>$ ), després podem veure una escola de primària funcionant de manera completa cercant el Power Point del Colegio Buzanada de Tenerife (<http://www.aprendizajesignificativo. es/2011/04/power-point-del-colegio-buzanadaexperiencia-global-de-centro-tenerife/>) i des- prés podem veure diverses experiències de primària, des de les més inicials fins a més avançades, al CD del seminari d'aprenentatge significatiu de les Canàries, a les experiències de primària.

De vegades, el professorat té la sensació que cada proposta innovadora que li arriba li suposarà una major càrrega de feina a canvi de resultats incerts, no contrastats. S'ha trobat amb aquesta premissa?

Sap quant de temps he tardat a fer la memòria aquest curs escolar? Dotze minuts. El 90\% dels apartats es respon amb una frase: "Ha anat bé. Continuar igual." Si tenim els alumnes bé, els papers es responen ràpid, evita molta literatura. Aquesta proposta innovadora de l'aprenentatge significatiu a la pràctica de l'aula porta un poc de feina al principi, però s'amortitza; en tenir sistematitzat el tema, el mestre fa molta menys feina. A l'escola tradicional el mestre és el que fa

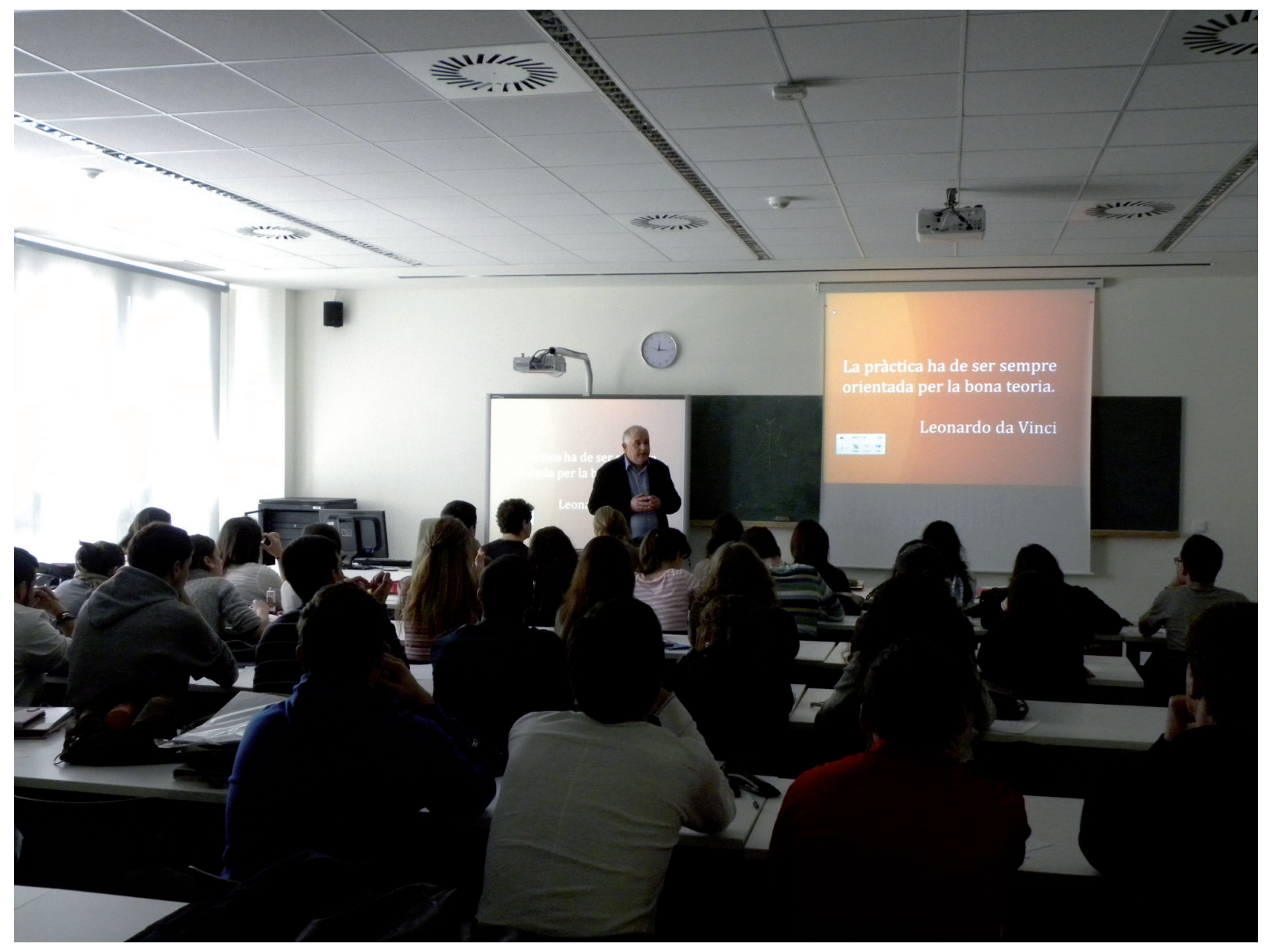


la feina i els alumnes estan passius, però el mestre ja sap l'assignatura, qui cal que l'aprengui és l'alumne. Per això cal que l'alumne faci la feina i el mestre coordini, supervisi... Arriba un moment que, en tenir la feina sistematitzada, molta part del temps no fa falta mestre, els alumnes funcionen sols!

Els alumnes a la classe fan dues coses majoritàriament: $\mathrm{o}$ treballen i aprenen o molesten. Ens interessa que treballin i aprenguin, si sistematitzam i feim que aprenguin, evitam molts de problemes, des del bulling fins als càstigs; el clima de l'aula és més relaxat, i el mestre esta més satisfet.

A les facultats d'educació es parla - potser massa- d'aprenentatge significatiu, però sovint només hi ha el vernís d'una teoria que fins pot arribar a ser buida i eixorca. En aquest sentit, què caldria millorar en la formació dels futurs mestres per poder aconseguir bons resultats?

No podem dir als futurs mestres de primària o secundària que facin l'aprenentatge significatiu i treball en equip i metodologies inclusives des de la tarima i amb explicació oral a la manera tradicional, estam desautoritzats si ho feim així.
La major part del professorat de magisteri, per anar bé, hauria d'haver treballat abans a primària o secundària, hauria d'haver estat a un nivell no universitari durant temps per poder posar exemples pràctics i que tingués credibilitat la seva proposta. Hi pot haver també alguns professors que no hagin treballat abans en l'àmbit no universitari, però haurien de ser pocs i haurien de visitar sovint els centres. Una proposta bona és que el professor universitari, un dia la setmana, faci, amb la companyia del mestre tutor i amb els alumnes de primària i secundària, totes les activitats normals que comporta una classe, des d'iniciar un tema fins a l'avaluació. Això es pot aconseguir demanant permís al mestre tutor, al director de l'escola i a la inspecció. A Youtube poden cercar "Aprenentatge significatiu. Exemples 3 ", on poden veure un vídeo de l'aprenentatge significatiu a la universitat.

Si hagués de fer un espot, amb un mapa conceptual, per engrescar el mestre a participar en aquest procés, com el faria?

"La pràctica ha de ser orientada per la bona teoria." Foto de Leonardo da Vinci.

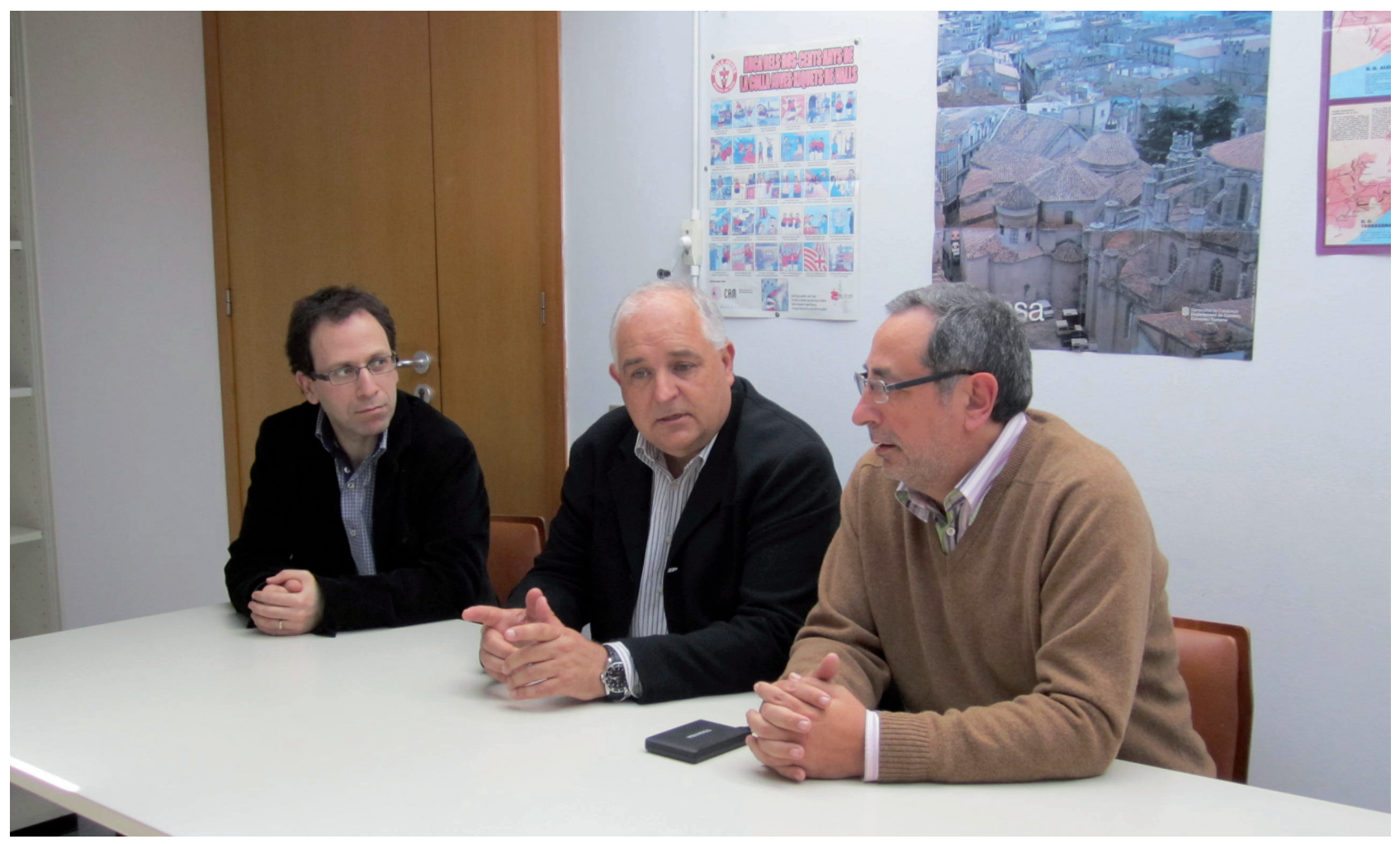


Imatges en vídeo del parc infantil del barri de l'escola amb els pares i mares. Amb la frase: "Com fas que un infant aprengui un concepte que no coneix?" Li poses un concepte més senzill que sap i l'hi relaciones. Per què, si a la vida real ho feim d'aquesta manera, a l'escola ho feim d'una altra?

\section{I si hagués d'engrescar els alumnes a partir d'un mapa conceptual, quin els presentaria?}

Els mapes conceptuals de la NASA. Un esforç de col-laboració entre l'Institute for Human and Machine Cognition i la NASA sobre l'ús de mapes conceptuals per explicar la raó de l'exploració espacial humana més enllà de l'òrbita baixa de la Terra ha estat, recentment, posat a disposició del públic. S'hi pot accedir des del web de la NASA a: $<$ http://www.nasa.gov/exploration/whyweexplore/cmap.html>, o directament al web de l'IHMC a: <http://spaceexp.ihmc.us $>$.

Segons Alberto Cañas, director associat del Research Scientist Institute for Human and Machine Cognition (IHMC, Pensacola, Florida), encara que no sestigui interessat en l'exploració de l'espai, la seva experiència li diu que els estudiants sovint pensen que és bo que la NASA utilitzi mapes conceptuals i pot servir com una motivació per a ells. Així que, si sou un mestre, és possible que vulgueu compartir l'enllaç amb ells. Els mapes conceptuals van ser fets usant CmapTools i el model inclou, aproximadament, més de 120 mapes conceptuals basats en el coneixement dels experts, més de 200 vídeos enllaçats d'entrevistes amb experts i científics fets específicament amb aquest objectiu, i més de 300 vídeos addicionals vinculats als Cmaps, també vinculats a centenars d'enllaços a imatges i pàgines web.

Vostè té una llarga experiència docent a educació obligatòria, $i$ ha vist passar tota mena de reformes legals i administratives. Quin balanç faria dels resultats obtinguts?

Fa més de 30 anys Francesco Tonucci, pedagog italià reconegut, va dir: "L’educació no la canvien les lleis, sinó els professors". Fa poc el professor Tonucci va venir a Espanya i va dir: "Les lleis no tenen tanta importància" perquè "no hi ha una llei tan dolenta que pugui fer dolent un bon mes- tre”. Jo me deman: hem d'esperar 30 anys més la propera frase del mestre Tonucci?

Els resultats obtinguts, com ja avisava Tonucci, són estèrils, inútils. Un mestre té en la seva vida entre dos i tres mil alumnes; per tant, és més important un mestre que el ministre d'Educació. El que sí que donaria resultats notables seria treure una llei que digués: Article 1: Els pares i mares han d'educar el seus fills i fer que vagin a escola a aprendre. Article 2: El mestres i professors també educaran completant l'educació dels pares i mares i, a més, ensenyaran, és a dir, faran que l'alumne aprengui. La manera de desenvolupar aquesta llei és senzilla: formar el professorat de veritat en la gestió de l'aula, els recursos didàctics i l'aprenentatge de l'alumne, així com conscienciar els mitjans de comunicació, els pares i mares de la importància d'educar els fills en l'honradesa i l'estudi. Finalment: fora tants de papers, deixar tranquils els centres, eliminar emplenar fitxes i posar creus als papers i a les graelles. Així segur que milloraríem el sistema de manera notable. És a dir, hi ha solució, es tracta de posar els mitjans per aconseguir-la.

Sovint, els bons desitjos provinents de l'administració no s'han traduït en una aplicació efectiva a les escoles. A banda de la falta de recursos econòmics, quins altres factors hi han afectat negativament?

Hi ha molts factors que hi afecten negativament, però hi ha cinc factors de què es parla poc i que si se solucionessin hi afectarien positivament: el primer, que els representants polítics i mitjans de comunicació diguin als pares i mares negligents que cal preocupar-se de l'educació dels seus fills i que la feina dels fills és anar a escola a estudiar; el segon, posar un assistent social a cada centre d'infantil i primària (per exemple, intervenir quan els pares i mares no van a les reunions de pares de l'escola, veurien què passa); el tercer, que tots els directors i directores dels centres educatius tenguin una bona formació psicopedagògica; el quart, que l'administració educativa, els directors, orientadors i caps d'estudis eliminin paperassa: un mestre sols hauria de rebre 10 folis en un any, i el cinquè, formar el professorat bé $a m b$ coses pràctiques que puguin fer i que fun- 
cionin, evitar màfies de ponents, formar en les innovacions que funcionen i els mestres les apliquen, perquè els mestres saben molt bé que quan apliquen de veritat una cosa és perquè funciona.

\section{Ens agradaria que hi afegís allò que cregui oportú.}

Sí, volia comentar tres coses. En aquesta innovació educativa, la prioritat són els infants, després els mestres, després el projecte i, finalment, el currículum personal. Si volem fer una bona innovació, hem de seguir sempre aquest ordre de prioritats en totes les decisions. Vos contaré un secret: fa uns anys tenia un article que havia de traduir a l'anglès i el professor Antoni Gavaldà me va demanar fer un article per a aquesta revista, Comunicació Educativa. Vaig decidir no publicar l'article en anglès encara que ho necessitava i era millor per al meu currículum i fer-ho en català a Tarragona, ja que era millor per als mestres i per als alumnes, tenia pocs articles en català i a una revista amb aquest títol; era millor que un congrés internacional. Per això sempre recordaré Tarragona i la importància de la Comunicació Educativa.

En segon lloc, vull agrair a tot el professorat, persones responsables i de l'administració de la URV de Tarragona i Tortosa les facilitats que m'han donat per fer aquestes xerrades a magisteri, especialment donar les gràcies al professor Antoni Gavaldà i la professora Núria Gil, amb els quals he tingut més comunicació aquests dies; igualment als alumnes de magisteri per les seves interessants i sempre estimulants preguntes amb les quals jo he hagut de reflexionar i també han fet que aprengui. M'agradaria molt poder repetir aquestes xerrades a altres universitats si el professorat i els alumnes ho troben oportú; per la meva part, posaré totes les facilitats que me siguin possibles.

En tercer lloc, volia comentar la frase de Nelson Mandela: "Leducació és la millor arma que pots usar per canviar el món." Segur que és posible, no es una bogeria, si cada pare i mare educa el seu fill i filla i cada mestre educa i ensenya i fa que aprenguin els seus alumnes. Amb comunicació educativa, és clar. 